\title{
Interaction between adolescent obesity and HLA risk genes in the etiology of multiple sclerosis
}

\section{OPEN}

Anna Karin Hedström, MD

Izaura Lima Bomfim,

$\mathrm{PhD}$

Lisa Barcellos, PhD

Milena Gianfrancesco, $\mathrm{MPH}$

Catherine Schaefer, PhD

Ingrid Kockum, $\mathrm{PhD}$

Tomas Olsson, PhD*

Lars Alfredsson, PhD*

Correspondence to

Dr. Hedström:

anna.hedstrom@ki.se

Editorial, page 826

Supplemental data at Neurology.org

\section{ABSTRACT}

Objective: We investigated potential interactions between human leukocyte antigen (HLA) genotype and body mass index (BMI) status in relation to the risk of developing multiple sclerosis (MS).

Methods: We used 2 case-control studies, one with incident cases (1,510 cases, 2,017 controls) and one with prevalent cases (937 cases, 609 controls). Subjects with different genotypes and $\mathrm{BMI}$ were compared with regard to incidence of MS by calculating odds ratios (ORs) with 95\% confidence intervals ( $\mathrm{Cls}$ ) employing logistic regression. Potential interactions between genotypes and BMI were evaluated by calculating the attributable proportion due to interaction.

Results: In both cohorts, a significant interaction was observed between HLA-DRB1*15 and obesity, regardless of HLA-A*02 status. Similarly, there was a significant interaction between absence of $\mathrm{A} * 02$ and obesity, regardless of DRB1*15 status. In the incident cohort, obese subjects with the most susceptible genotype (carriage of DRB1*15 and absence of $A * 02$ ) had an OR of 16.2 (95\% Cl 7.5-35.2) compared to nonobese subjects without the genetic risk factors. The corresponding OR in the prevalent study was 13.8 (95\% Cl 4.1-46.8).

Conclusions: We observed striking interactions between BMI status and HLA genotype with regard to MS risk. Hypothetically, a low-grade inflammatory response inherent to obesity synergizes with the adaptive, HLA molecule-restricted arm of the immune system, causing MS. Prevention of adolescent obesity may thus lower the risk of developing MS, predominantly among people with a genetic susceptibility to the disease. Neurology ${ }^{\circledR} 2014 ; 82: 865-872$

\section{GLOSSARY}

$\mathbf{A P}=$ attributable proportion due to interaction; $\mathbf{B M I}=$ body mass index; $\mathbf{C l}=$ confidence interval; $\mathbf{E A E}=$ experimental autoimmune encephalomyelitis; EIMS = Epidemiological Investigation of MS; HLA = human leukocyte antigen; KPNC = Kaiser Permanente Medical Care Plan, Northern California Region; MS = multiple sclerosis; OR = odds ratio; SNP = single nucleotide polymorphism.

Multiple sclerosis (MS) is an inflammatory demyelinating disorder of the CNS, and the most common nontraumatic cause of acquired neurologic disability affecting young adults. Susceptibility to MS is determined by both genetic and environmental factors. A relationship between obesity in early life and increased MS risk has been demonstrated in 3 previous studies. ${ }^{1-3} \mathrm{~A}$ potential mechanism for the association has been suggested in that obese people have lower levels of vitamin D metabolites than do normal-weight people and decreased levels of serum 25hydroxyvitamin D appear to increase MS risk. Furthermore, fat-related chronic inflammation may be involved. Adipose tissue produces and releases a variety of proinflammatory cytokines, including leptin, which promotes Th1 responses and reduces regulatory T-cell activity. ${ }^{4}$

The hitherto known lifestyle/environmental factors associated with MS have only modest impact on the risk of developing the disease. The recently demonstrated gene-environment

\footnotetext{
*These authors contributed equally to this work.

From the Institute of Environmental Medicine (A.K.H.), Neuroimmunology Unit, Department of Clinical Neuroscience (I.L.B., I.K.), and the Institute of Environmental Medicine (L.A.), Karolinska Institutet, Stockholm, Sweden; Genetic Epidemiology and Genomics Lab (L.B., M.G.), Division of Epidemiology, School of Public Health, University of California, Berkeley; Kaiser Permanente Division of Research (C.S.), Oakland, CA; Center for Molecular Medicine (I.K.) and Neuroimmunology Unit, Department of Clinical Neuroscience and Center for Molecular Medicine (T.O.), Karolinska Institutet at Karolinska University Hospital, Solna; and Centre for Occupational and Environmental Medicine (L.A.), Stockholm County Council, Sweden.

Go to Neurology.org for full disclosures. Funding information and disclosures deemed relevant by the authors, if any, are provided at the end of the article. This is an open access article distributed under the terms of the Creative Commons Attribution-Noncommercial No Derivative 3.0 License, which permits downloading and sharing the work provided it is properly cited. The work cannot be changed in any way or used commercially.
} 
interactions with regard to MS risk show that the risk conveyed by lifestyle/environmental factors may substantially differ depending on genetic background. 5,6

Using a Swedish population-based case-control study as well as an American case-control study, we studied the potential interaction between adolescent obesity and the most strongly associated genes in MS: the human leukocyte antigen (HLA)-DRB1*15 allele, which provides an increased risk with odds ratios (ORs) in the order of $\sim 3$, and the HLA-A*02 allele (figure), which reproducibly has shown a protective association to MS.7,8

METHODS Design and study population. This report is based on data from 2 case-control studies on environmental and genetic risk factors for MS. The first study is the Epidemiological Investigation of MS (EIMS), with a study base comprising the Swedish population aged 16 to 70 years. Incident cases were recruited via 40 clinics, including all university hospitals in Sweden. A case was defined as a person in the study base who had received a diagnosis of MS according to the McDonald criteria. ${ }^{9}$ For each case, 2 controls were randomly selected from the national population register, frequency matched by age ( 5 -year age groups), sex, and residential area. Information regarding exposures and other circumstances was collected using a standardized questionnaire that was filled in at home. The study period for this report was April 2005 to March 2012. Completed questionnaires were obtained from 1,798 cases and 3,907 controls, which is equivalent to $91 \%$ for the case group and $69 \%$ for the controls. Since the impact of adolescent obesity was investigated in this study, cases with disease onset before age 20 , and their corresponding controls, were excluded (110 cases, 218 controls).

The American case-control study used a study population of white non-Hispanic people identified among members of Kaiser Permanente Medical Care Plan, Northern California Region (KPNC), using electronic medical records. KPNC is an integrated health services delivery system with a membership of 3.2 million that comprises about $25 \%$ to $30 \%$ of the population of a 22-county service area in northern California. Cases of MS were required to have an MS diagnosis by a neurologist, self-identified white race/ethnicity, age 18 through 69 years, and KPNC membership at initial contact. Controls were randomly selected from current KPNC members who did not have a MS diagnosis or related conditions, and were individually matched to cases on sex, birth date, race/ethnicity, and zip code of the case residence. In total, 1,087 cases and 687 controls were included in this report; 128 cases with disease onset before age 20 were excluded, and 23 cases and 14 controls were excluded due to missing data on body mass index (BMI). The response rate was $79 \%$ for cases

Figure Interaction among adolescent obesity, carriage of HLA-DRB1*15, and absence of HLA-A*02
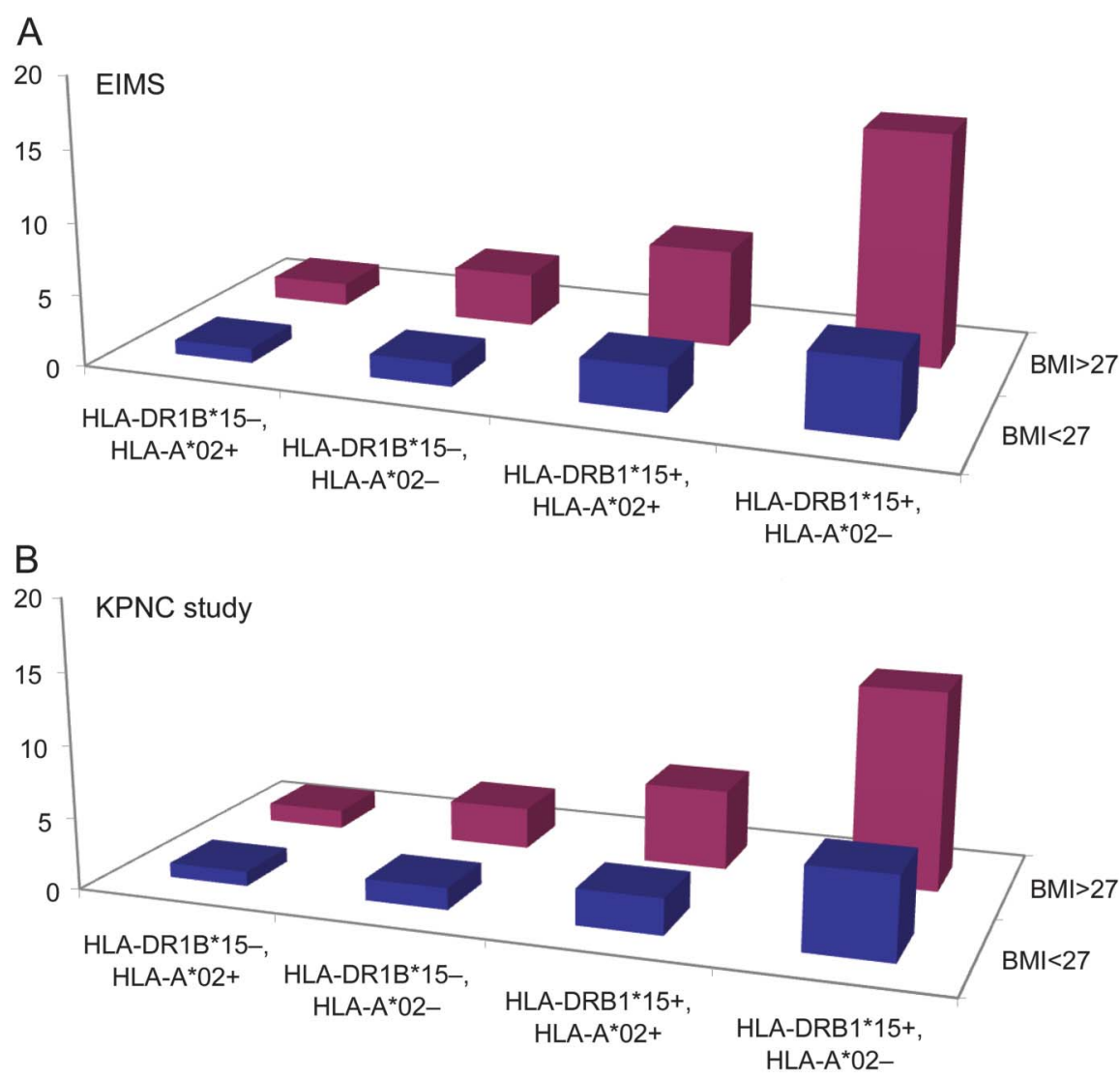

(A) Epidemiological Investigation of MS (EIMS) study. (B) Kaiser Permanente Medical Care Plan, Northern California Region (KPNC) study. Odds ratios for different combinations of body mass index (BMI), human leukocyte antigen (HLA)-DRB1*15, and HLA-A*02 status, with regard to the risk of developing multiple sclerosis. Statistics are shown in table 4. 
and $58 \%$ for controls. All participants completed a computerassisted telephone interview regarding lifestyle factors and exposures.

Standard protocol approvals, registrations, and patient consents. EIMS was approved by the Regional Ethical Review Board at Karolinska Institutet. The KPNC study protocol was approved by the institutional review boards of KP Division of Research and the University of California, Berkeley.

Genotyping. In EIMS, blood samples were available from 1,510 cases $(89 \%)$ and 2,017 controls (55\%). Allelic dosage of HLADRB1*15 and HLA-A*02 was obtained by 1 of 3 methods: (1) PCR amplification with sequence-specific primers (Olerup SSP low resolution typing kits, Olerup SSP AB, Stockholm, Sweden); (2) imputation using HLA*IMP:02 $2^{10}$ based on single nucleotide polymorphisms (SNPs) genotyped on the Immunochip custom array $^{11}$ in an overlapping Swedish cohort; or (3) TaqMan allelic discrimination of the SNPs rs9271366 (assay ID: C_33416976_20), which tags HLA-DRB1*15 or rs2975033 (assay ID: C_15962692_20) and rs12206499 (assay ID: C_31338281_10), which combined tags for HLA-A*02. The distribution of method for classification of HLA-DRB1*15 status was as follows: $67 \%$ of cases $/ 64 \%$ of controls were genotyped with the Olerups SSP kit, $4 \%$ cases $/ 1 \%$ controls had imputed genotypes, and $29 \%$ cases $35 \%$ controls were genotyped with TaqMan genotyping assays. The figures for distribution of method for classification of HLA-A*02 status were the same with the exception of percentage of cases that were genotyped with Olerups kit, which was $66 \%$ for HLA-A*02 status. In the KPNC study, information on HLA genotype was available for 937 (86\%) cases and $609(87 \%)$ controls. HLA-DRB1 genotypes were determined by use of a sequence-specific PCR method, as previously described. ${ }^{12}$ Allelic dosage of HLA-A*02 was obtained by TaqMan allelic discrimination of the SNPs rs2975033 (assay ID: C_15962692_20), which tags for HLA-A*02. The validity of imputing HLA types from SNPs has been studied against classical methods of HLA typing and congruence between methods is very good for most alleles, including HLA-DRB1*15 and HLA-A*02, studied herein. ${ }^{10,13}$ Participants in both studies were classified according to the carriage of any HLA-DRB1*15 allele vs no carriage, and according to carriage of any HLA-A*02 allele vs no carriage (where absence of HLA-A* 02 is the risk factor).

Body mass index. The questionnaire in EIMS contained questions regarding demographic factors, lifestyle factors, and socioeconomic circumstances. Information was obtained regarding current body height and body weight at age 20. Using current height, we calculated BMI at age 20 by dividing weight in kilograms by height in meters squared.

In the KPNC study, participants reported their current height at the time of the interview, as well as their highest and lowest (nonpregnancy) weight during their 20s. Using current height, BMI during their 20 s was calculated by dividing mean weight in kilograms by height in meters squared.

In order to analyze the influence of BMI on the risk of developing MS, we categorized the subjects into the following groups based on $\mathrm{BMI}:<18.5,18.5-<21,21-<23,23-<25,25-<27$, and $\geq 27 \mathrm{~kg} / \mathrm{m}^{2}$. The typical standard for obesity is BMI $>30 \mathrm{~kg} / \mathrm{m}^{2}$. However, in EIMS, fewer than $2 \%$ had an adolescent BMI exceeding $30 \mathrm{~kg} / \mathrm{m}^{2}$. The OR among subjects with BMI 27-30 and $>30$ was fairly similar (BMI 27-30: OR 2.1, 95\% confidence interval [CI] 1.4-3.0; and BMI >30: OR 2.5, 95\% CI 1.7-3.7). Therefore, we chose to combine these BMI groups into one group defined as obese.

Statistical analysis. By means of unconditional logistic regression, the incidence of MS in subjects belonging to different
BMI groups was compared with that of normal-weight subjects with BMI between 18.5 and $21 \mathrm{~kg} / \mathrm{m},{ }^{2}$ by calculating ORs with 95\% CIs. Trend test for a dose-response relationship regarding adolescent BMI and risk of MS was performed by using a continuous variable for BMI $\left(\mathrm{kg} / \mathrm{m}^{2}\right)$ in a logistic regression model. Analyses of interaction between BMI and HLA-DRB1-15 as well as between BMI and HLA-A*02 were performed, and the possible gene-environment interaction was evaluated by estimating departure from additivity of effects using attributable proportion due to interaction (AP) as described..$^{14,15}$

In EIMS, we also performed conditional logistic regression. However, only the results from the unmatched analyses are presented in this report since these were in close agreement with those from the matched analyses but had a higher degree of precision (due to a higher number of controls). In the KPNC study, there were far more cases than controls, and in order to use information from the whole group we conducted unconditional logistic regression with adjustment for the matching factors.

In EIMS, all analyses were adjusted for age, sex, and residential area as well as for ancestry and smoking. Age was categorized into the following 8 strata: 16-19, 20-24, 25-29, 30-34, 35-39, $40-45,45-49$, and 50-70 years of age. Assessment of ancestry was based on whether the subject was born in Sweden or not, and whether either of the subject's parents had immigrated to Sweden. A subject who was born in Sweden, whose parents had not immigrated, was classified as Swedish. Smoking was dichotomized as ever or never-smokers. Smoking was considered prior to the index year in the cases (i.e., the year of disease onset) and during the same period of time in the corresponding controls. Adjustments were also made for heredity (having a first- or second-degree relative with MS or not), educational level (university degree or not), socioeconomic status (according to an established socioeconomic classification), ${ }^{16}$ physical activity during ages 18 to 22 (yes/no), oral contraceptive use (ever/never), parity (yes/no), EBNA1-immunoglobulin G (high/low), vitamin D status (more or less than $50 \mathrm{ng} / \mathrm{mL}$ ), and ultraviolet radiation exposure habits (high/low), but these factors had minor influence on the results of the study and were not retained in the final analyses. All analyses were conducted using SAS version 9.2.

In the KPNC study, adjustments were made for age, sex, ancestry, and smoking. Age was categorized in the same manner as in EIMS. Ancestry was categorized into the following stratas: Northern Europe, Western Europe, Southern Europe, Eastern Europe, other, and unknown. Smoking was dichotomized as smokers or nonsmokers at age 20 .

RESULTS Selected characteristics of subjects by study and BMI at age 20 are presented in table e- 1 on the Neurology ${ }^{\circledR}$ Web site at Neurology.org.

In both studies, subjects with adolescent BMI $\geq 27 \mathrm{~kg} / \mathrm{m}^{2}$ had an increased risk of developing MS compared to normal-weight subjects with BMI between 18.5 and $21 \mathrm{~kg} / \mathrm{m}^{2}$ (OR 2.2 [95\% CI 1.73.0] in EIMS and 1.8 [95\% CI 1.2-2.6] in the KPNC study) (table 1). MS risk in subjects with BMI between 25 and $27 \mathrm{~kg} / \mathrm{m}^{2}$ was modestly increased (OR 1.4 [95\% CI 1.05-1.9] in EIMS and 1.3 [95\% CI 0.92.0] in the KPNC study). The observed trend of a higher BMI resulting in a higher risk of developing MS was statistically significant in both studies. The ORs remained unchanged when the analyses were restricted to those who had been genotyped. 


\begin{tabular}{|c|c|c|c|c|c|c|}
\hline \multirow{3}{*}{$\begin{array}{l}\text { Table } 1 \\
\text { BMl, kg/m² }\end{array}$} & \multicolumn{6}{|c|}{$\begin{array}{l}\text { Odds ratios with } 95 \% \text { confidence intervals of developing multiple sclerosis for subjects in different } \\
\text { categories according to body mass index at age } 20 \text { compared with normal-weight subjects }\end{array}$} \\
\hline & \multicolumn{3}{|l|}{ EIMS } & \multicolumn{3}{|c|}{ KPNC study } \\
\hline & $\mathrm{Ca} / \mathrm{co}^{\mathrm{a}}$ & OR $(95 \% \mathrm{Cl})^{\mathrm{b}}$ & $p$ & $\mathrm{Ca} / \mathrm{co}^{\mathrm{a}}$ & OR $(95 \% \mathrm{Cl})^{\mathrm{c}}$ & $p$ \\
\hline$<18.5$ & $126 / 197$ & $1.0(0.8-1.3)$ & 0.9 & $86 / 65$ & $1.0(0.7-1.4)$ & 0.8 \\
\hline $18.5-21$ & $462 / 711$ & 1.0 (reference) & & $278 / 208$ & 1.0 (reference) & \\
\hline $21-23$ & $381 / 550$ & $1.1(0.9-1.3)$ & 0.5 & $214 / 147$ & $1.0(0.8-1.4)$ & 0.9 \\
\hline $23-25$ & $283 / 337$ & $1.3(1.05-1.6)$ & 0.01 & $155 / 96$ & $1.1(0.8-1.5)$ & 0.6 \\
\hline $25-27$ & $110 / 121$ & 1.4 (1.05-1.9) & 0.02 & $84 / 44$ & $1.3(0.9-2.0)$ & 0.2 \\
\hline$\geq 27$ & $148 / 101$ & $2.2(1.7-3.0)$ & $<0.0001$ & $120 / 49$ & $1.8(1.2-2.6)$ & 0.006 \\
\hline$p$ for trend & & & $<0.0001$ & & & 0.005 \\
\hline
\end{tabular}

Abbreviations: $\mathrm{BMI}=$ body mass index; $\mathrm{Cl}=$ confidence interval; EIMS = Epidemiological Investigation of MS; KPNC = Kaiser Permanente Medical Care Plan, Northern California Region; OR = odds ratio.

${ }^{a}$ Exposed cases and controls.

${ }^{\mathrm{b}}$ Adjusted for age, sex, residential area (according to study design), ancestry, and smoking.

${ }^{\mathrm{c}}$ Adjusted for age, sex, ancestry, and smoking.

A significant interaction was observed between the HLA-DRB1* 15 allele and obesity with regard to risk for MS (table 2). The interaction was restricted to those with BMI $\geq 27 \mathrm{~kg} / \mathrm{m}^{2}$ (AP 0.6, 95\% CI $0.3-$ 0.8 in EIMS and AP 0.5, 95\% CI $0.2-0.9$ in the KPNC study). When the analysis of interaction between HLA-DRB1*15 and obesity (in categories:
DRB1*15-/BMI <27, DRB1*15+/BMI <27, DRB1*15-/BMI $\geq 27$, and DRB1*15+/BMI $\geq 27$ ) was performed by HLA-A*02 status in both materials combined, the AP was statistically significant in each strata ( $p$ value 0.0003 among HLA-A*02positive subjects and $<0.0001$ among HLA-A*02negative subjects).

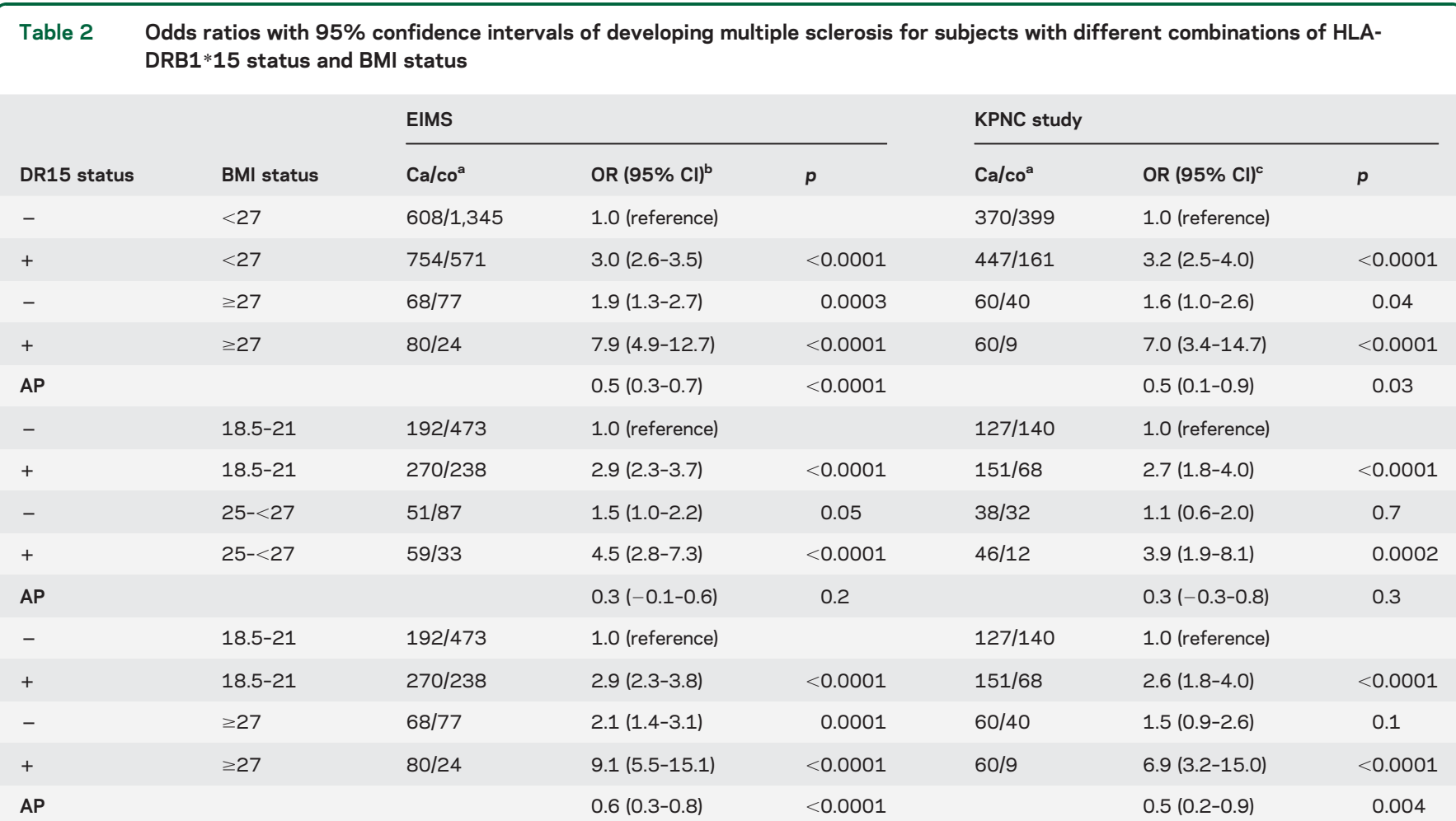

Abbreviations: $\mathrm{AP}=$ attributable proportion due to interaction between HLA-DRB1*15 and obesity; $\mathrm{BMI}=$ body mass index; $\mathrm{Cl}=$ confidence interval; EIMS = Epidemiological Investigation of MS; HLA = human leukocyte antigen; KPNC = Kaiser Permanente Medical Care Plan, Northern California Region; $\mathrm{OR}=$ odds ratio.

${ }^{a}$ Number of cases and controls.

${ }^{b}$ Adjusted for age, sex, residential area (according to study design), ancestry, smoking, and HLA-A*02 status.

${ }^{\mathrm{c}}$ Adjusted for age, sex, ancestry, smoking, and HLA-A*02 status. 
Table 3 Odds ratios with $95 \%$ confidence intervals of developing multiple sclerosis for subjects with different combinations of HLA-A*02 status and BMI status

\begin{tabular}{|c|c|c|c|c|c|c|c|}
\hline A2 status & BMI status & \multicolumn{3}{|l|}{ EIMS } & \multicolumn{3}{|c|}{ KPNC study } \\
\hline+ & $<27$ & $582 / 1,050$ & 1.0 (reference) & & $306 / 282$ & 1.0 (reference) & \\
\hline- & $<27$ & $780 / 866$ & $1.7(1.5-2.1)$ & $<0.0001$ & $511 / 278$ & $1.7(1.4-2.2)$ & $<0.0001$ \\
\hline+ & $\geq 27$ & $60 / 57$ & $1.8(1.2-2.7)$ & 0.002 & $44 / 25$ & $1.6(0.9-2.9)$ & 0.1 \\
\hline+ & $18.5-21$ & $200 / 382$ & 1.0 (reference) & & $106 / 99$ & 1.0 (reference) & \\
\hline- & $18.5-21$ & $262 / 329$ & $1.6(1.3-2.1)$ & $<0.0001$ & $172 / 109$ & $1.4(0.9-2.1)$ & 0.1 \\
\hline+ & $25-<27$ & $46 / 61$ & $1.6(1.0-2.5)$ & 0.04 & $31 / 21$ & $1.0(0.5-2.1)$ & 0.9 \\
\hline- & $25-<27$ & $64 / 59$ & $2.4(1.6-3.6)$ & $<0.0001$ & $53 / 23$ & $2.0(1.1-3.8)$ & 0.03 \\
\hline+ & $\geq 27$ & $60 / 57$ & $2.1(1.4-3.2)$ & 0.0007 & $44 / 25$ & $1.4(0.7-2.7)$ & 0.3 \\
\hline- & $\geq 27$ & $88 / 44$ & 4.8 (3.1-7.3) & $<0.0001$ & $76 / 24$ & $3.1(1.7-5.6)$ & 0.0002 \\
\hline AP & & & $0.4(0.1-0.7)$ & 0.004 & & $0.4(0.01-0.8)$ & 0.04 \\
\hline
\end{tabular}

Abbreviations: $\mathrm{AP}=$ attributable proportion due to interaction between $\mathrm{HLA}-\mathrm{A} * 02$ and obesity; $\mathrm{BMI}=$ body mass index; $\mathrm{Cl}=$ confidence interval; $\mathrm{EIMS}=$ Epidemiological Investigation of MS; HLA = human leukocyte antigen; KPNC = Kaiser Permanente Medical Care Plan, Northern California Region; OR = odds ratio.

${ }^{a}$ Number of cases and controls.

${ }^{\mathrm{b}}$ Adjusted for age, sex, residential area (according to study design), ancestry, smoking, and HLA-DRB1*15 status.

${ }^{c}$ Adjusted for age, sex, ancestry, smoking, and HLA-DRB1*15 status.

Similarly, a significant interaction was observed between absence of HLA-A*02 and obesity (AP 0.4, 95\% CI 0.1-0.7 in EIMS and AP 0.4, 95\% CI 0.010.8 in the KPNC study) (table 3). When the analysis of interaction between absence of HLA-A*02 and obesity (in categories: $\mathrm{A}^{*} 02+/ \mathrm{BMI}<27, \mathrm{~A}^{*} 02-/ \mathrm{BMI}<27$, $\mathrm{A} * 02+/ \mathrm{BMI} \geq 27$, and $\mathrm{A} * 02-/ \mathrm{BMI} \geq 27$ ) was performed by HLA-DRB1*15 status in both materials combined, the AP was statistically significant in each strata ( $p$ value 0.02 among HLA-DRB1*15-negative subjects and 0.01 among HLA-DRB1*15-positive subjects).

The magnitude of interaction between HLADRB $1 * 15$ and adolescent obesity remained the same regardless of which reference group was used (table e-2). Finally, we calculated the ORs associated with the most susceptible genotype (carriage of DRB $1 * 15$ but not HLA-A*02) in subjects with BMI more or less than $27 \mathrm{~kg} / \mathrm{m}^{2}$, respectively, compared with nonobese subjects without these genetic risk factors. Subjects with BMI less than $27 \mathrm{~kg} / \mathrm{m}^{2}$ with the 2 risk genotypes displayed an OR of 5.1 (95\% CI 4.1-6.3), whereas the same genotype for subjects with BMI $\geq 27 \mathrm{~kg} / \mathrm{m}$ rendered an OR of 16.2 (95\% CI 7.5-35.2). The corresponding ORs in the KPNC study were 5.7 (4.0-8.0) and 13.8 (4.1-46.8) (table 4).
DISCUSSION We demonstrate striking interactions between adolescent obesity and 2 potent MS risk genes, properly replicated in an independent material, similar to the interaction between carriage of HLADRB $1 * 15$, absence of HLA-A*02, and smoking in the development of MS. ${ }^{5}$ The biological explanations for these interactions are far from clear, but the data open up for mechanistically oriented studies. It should be emphasized that interaction measured this way does not necessarily imply evidence for direct protein-protein interactions such as in a ligandreceptor pair, but rather indicates that the factors act synergistically in the same pathogenic pathway. In case of the BMI-HLA MS risk gene interaction, we primarily consider a low-grade chronic inflammation with activation of the innate immune system, promoted by the fat tissue, ${ }^{4}$ which may increase the options for HLA-restricted activation of autoreactive T cells attacking the CNS in MS.

It is important to consider potential drawbacks, confounders, or biases in our study. Both studies retrospectively gathered information regarding lifestyle factors and personal information such as weight and height. EIMS primarily included cases who had received the diagnosis within the past year in order to minimize recall bias. Moreover, the questionnaire 


\begin{tabular}{|c|c|c|c|c|c|c|c|c|c|}
\hline \multirow{3}{*}{$\begin{array}{l}\text { Table } 4 \\
\text { DR15 }\end{array}$} & \multicolumn{9}{|c|}{$\begin{array}{l}\text { Odds ratios with } 95 \% \text { confidence intervals of developing multiple sclerosis for subjects with different combinations of } B M I \text { and the } \\
\text { genetic risk factors carriage of the HLA-DRB } 1 * 15 \text { allele and absence of the HLA-A } * 02 \text { allele, compared with nonobese subjects } \\
\text { carrying none of the genetic risk factors }\end{array}$} \\
\hline & \multirow[b]{2}{*}{$\mathrm{A} 2$} & \multirow[b]{2}{*}{$\mathrm{BMI} \geq 27$} & \multicolumn{3}{|l|}{ EIMS } & \multicolumn{4}{|l|}{ KPNC study } \\
\hline & & & $\mathrm{Ca} / \mathrm{co}^{\mathrm{a}}$ & OR $(95 \% \mathrm{Cl})^{\mathrm{b}}$ & $p$ & OR $(95 \% \mathrm{CI})^{\mathrm{c}}$ & $\mathrm{Ca} / \mathrm{co}^{\mathrm{a}}$ & OR $(95 \% \mathrm{Cl})^{d}$ & p \\
\hline- & + & - & 249/723 & 1.0 (reference) & & 1.0 (reference) & $136 / 192$ & 1.0 (reference) & \\
\hline- & - & - & $359 / 622$ & $1.6(1.4-2.0)$ & $<0.0001$ & $1.7(1.4-2.1)$ & $234 / 207$ & $1.5(1.1-2.0)$ & 0.009 \\
\hline+ & + & - & 333/327 & $3.0(2.4-3.7)$ & $<0.0001$ & 3.1 (2.5-3.9) & $170 / 90$ & $2.5(1.8-3.6)$ & $<0.0001$ \\
\hline+ & - & - & $421 / 244$ & $5.1(4.1-6.3)$ & $<0.0001$ & $5.3(4.3-6.7)$ & $277 / 71$ & $5.7(4.0-8.0)$ & $<0.0001$ \\
\hline- & + & + & $23 / 41$ & $1.6(0.9-2.7)$ & 0.1 & $1.4(0.8-2.4)$ & $18 / 19$ & $1.3(0.6-2.7)$ & 0.5 \\
\hline- & - & + & $45 / 36$ & $3.7(2.3-5.8)$ & $<0.0001$ & $3.5(2.1-5.6)$ & $42 / 21$ & $2.9(1.6-5.3)$ & 0.0007 \\
\hline+ & + & + & $37 / 16$ & 6.8 (3.7-12.5) & $<0.0001$ & 6.5 (2.1-12.0) & $26 / 6$ & $5.6(2.2-14.4)$ & 0.0003 \\
\hline+ & - & + & $43 / 8$ & 16.2 (7.5-35.2) & $<0.0001$ & $15.9(7.3-34.7)$ & $34 / 3$ & $13.8(4.1-46.8)$ & $<0.001$ \\
\hline
\end{tabular}

Abbreviations: $\mathrm{BMI}=$ body mass index; $\mathrm{Cl}=$ confidence interval; EIMS = Epidemiological Investigation of MS; HLA = human leukocyte antigen; KPNC = Kaiser Permanente Medical Care Plan, Northern California Region; OR = odds ratio.

${ }^{a}$ Number of cases and controls.

${ }^{\mathrm{b}}$ Adjusted for age, sex, residential area (according to study design), ancestry, and smoking.

${ }^{\mathrm{c}}$ Adjusted for age, sex, residential area (according to study design), ancestry, smoking, heredity, educational level, socioeconomic status, physical activity during ages 18 to 22, oral contraceptive use, parity, EBNA1-immunoglobulin G, vitamin D status, and ultraviolet radiation habits.

${ }^{\mathrm{d}}$ Adjusted for age, sex, ancestry, and smoking.

contained a wide range of questions regarding many potential environmental risk factors and no section in the questionnaire was given prime focus. The KPNC study was based on prevalent cases of MS. Thus, recall bias may have distorted the results. However, a validation study among women in the Nurses' Health Study found high correlations between recalled and measured past weight, and between reported current height and measured past height. ${ }^{17}$ Participants slightly underreported weight at 18 years of age with a mean difference of $1.4 \mathrm{~kg}$. The underreporting of weight probably does not differ between cases and controls. There is no reason to believe that the results would be different in other populations. Furthermore, body weight at age 30 was available in the American study, and no association was observed between BMI at age 30 and MS risk, which makes recall differences between cases and controls unlikely. Any recall bias regarding weight would tend to bias toward the null, thus underestimating the OR.

The proportion of respondents with regard to participation in EIMS was $91 \%$ for cases and 69\% for controls. A potential selection bias may result from the relatively high proportion of nonresponders among the controls. However, this bias is most likely to be modest because the prevalence of smoking among the controls, seen as an indicator of lifestyle, was in line with that of the general population at equivalent ages. ${ }^{18}$ Furthermore, the increased risk for MS associated with overweight and obesity was similar among those who provided blood and those who did not.

The molecular pathways responsible for the observed association between adolescent obesity and
MS are still unknown, but there are different hypotheses attempting to explain the association. High levels of circulating 25-hydroxyvitamin D have been associated with reduced risk of MS in early adulthood. ${ }^{19}$ Total body fat is inversely related to the levels of circulating 25-hydroxyvitamin D and consequently, obese people have lower levels of this metabolite than normal-weight people. ${ }^{20}$ The higher risk of MS among subjects who were obese during adolescence is consistent with a protective effect of vitamin D. However, our results based on EIMS remained unchanged when the analyses were adjusted for sun exposure habits and vitamin D status. Furthermore, both sun exposure habits and vitamin D status seem to affect MS risk in adults independently of HLA risk genes. ${ }^{21}$

We hypothesize that obesity-related inflammatory/ immunologic mechanisms contribute to explain the association between adolescent obesity and increased MS risk. Obesity induces a state of chronic, lowgrade inflammation ${ }^{22}$ that arises from the production and secretion of inflammatory mediators driven by adipose tissue macrophages. The number of macrophages present in adipose tissue is directly correlated with adiposity. ${ }^{23}$ Upon high fat feeding, adipose tissue macrophages undergo a phenotypic switch from an anti-inflammatory M2 polarization state to a proinflammatory M1 polarization. ${ }^{24} \mathrm{~A}$ recently published study demonstrated that the M1/M2 equilibrium in blood and CNS favors mild experimental autoimmune encephalomyelitis (EAE), whereas imbalance toward M1 promotes relapsing EAE. ${ }^{25}$

Leptin is produced mainly by adipose tissue in proportion to body fat mass ${ }^{26}$ and has been considered a 
link among obesity, metabolic state, and autoimmunity. Leptin promotes proliferation of effector $\mathrm{T}$ cells and constrains expansion of regulatory $\mathrm{T}$ cells, generally switching the phenotype toward a Th1 response, ${ }^{4}$ promoting the onset and progression of autoimmune responses. In the early stages of MS, an inverse correlation has been demonstrated between serum leptin concentration and the number of regulatory T-cells, which are known to dampen autoreactive responses mediated by CD4 + cells. ${ }^{27}$ Leptin-deficient mice have been shown to be resistant to EAE. This protection is reversed by leptin administration and is associated with a switch from Th2- to Th1-type responses. ${ }^{28}$

Obesity has been associated with increased susceptibility to inflammatory and autoimmune diseases such as psoriasis, autoimmune thyroiditis, diabetes, and MS. The increased incidence of both diabetes ${ }^{29}$ and $\mathrm{MS}^{30}$ has been parallel with the rise in childhood obesity. ${ }^{31,32}$ The finding of an interaction between obesity and HLA genotype with regard to MS supports the hypothesis that the Th1-promoting effects of obesity increase the risk of developing MS, in particular among subjects with a genetic susceptibility to the disease. An increased expression of HLA class II genes has been observed in adipose tissue macrophages specifically recruited to adipose tissue. ${ }^{33}$ The prime function of the molecules encoded by these genes is antigen presentation to $\mathrm{T}$ cells, and strong experimental data suggest that the association between HLA genotype and MS risk depends on preferences in peptides allowing CNSdirected autoimmunity. ${ }^{34}$

We thus hypothesize that by increasing the release of proinflammatory cytokines and promoting Th1 responses, and decreasing the number of regulatory $\mathrm{T}$ cells, obesity may increase the risk of recruitment of autoaggressive $\mathrm{CD} 4+$ cells that target $\mathrm{CNS}$ autoantigens. Obesity in the context of HLA risk genes may then further increase the risk of autoaggressive immunity that results in MS.

\section{AUTHOR CONTRIBUTIONS}

L.A. and T.O. supervised the EIMS project. C.S. and L.B. supervised the Kaiser study. A.K.H. performed the statistical analyses and drafted the manuscript. L.A. was engaged in interpreting the analysis. All authors helped in revising the manuscript. All authors approved the final version of the manuscript to be published.

\section{ACKNOWLEDGMENT}

The authors thank Karin Kai-Larsen, Linda Jonsson, and Eva Johansson for work with the collection of data in the EIMS study, and Nikolaos Patsopoulos, Janelle Noble, and Julie Lane for assistance with HLA-DRB1 genotyping.

\section{STUDY FUNDING}

Supported by the following grants: the Swedish Research Council for Health, Working Life and Welfare, the Knut and Alice Wallenberg Foundation, the AFA Foundation, the Swedish Brain Foundation, the Swedish Association for Persons with Neurological Disabilities, NIH/National Institute of Neurological Disorders and Stroke R01 NS049510, R01 NS0495103, and NIH/NIAID R01 AI076544.

\section{DISCLOSURE}

A. Hedström, I. Lima Bomfim, L. Barcellos, M. Gianfrancesca, C. Schaefer, and I. Kockum report no disclosures. T. Olsson served on scientific advisory boards for Merck-Serono, Biogen Idec, and SanofiAventis; served as Co-editor of Current Opinion in Immunology; received speaker honoraria from Novartis and Biogen; and receives research support from Bayer Schering, Sanofi-Aventis, Biogen Idec, the Swedish Research Council (07488), EU fp6 Neuropromise (LSHM-CT-2005-018637), EURATools (LSHG-CT-2005-019015), the Söderberg Foundation, Bibbi and Nils Jensens Foundation, the Montel Williams Foundation, and the Swedish Brain Foundation. L. Alfredsson receives research support from the Swedish Medical Research Council (K2007-69X-1497304-3) and Swedish Council for Working Life and Social Research (Dnr 2006-0655). Go to Neurology.org for full disclosures.

Received June 14, 2013. Accepted in final form November 1, 2013.

\section{REFERENCES}

1. Munger K, Chitnis T, Ascherio A. Body size and risk of MS in two cohorts of US women. Neurology 2009;73: 1543-1550.

2. Hedström AK, Olsson T, Alfredsson L. High body mass index before age 20 is associated with increased risk for multiple sclerosis in both men and women. Mult Scler 2012;18:1334-1336.

3. Langer-Gould A, Brara SM, Beaber BE, Koebnick C. Childhood obesity and risk of pediatric multiple sclerosis and clinically isolated syndrome. Neurology 2013;5: 548-552.

4. Matarese G, Procaccini C, De Rosa V. The intricate interface between immune and metabolic regulation: a role for leptin in the pathogenesis of multiple sclerosis? J Leukoc Biol 2008;84:893-899.

5. Hedstrom AK, Sundqvist E, Baarnhielm M, Olsson T, Alfredsson L. Smoking and two HLA genes interact to increase the risk for multiple sclerosis. Brain 2011;134: 653-664.

6. Sundqvist E, Sundström P, Lindén M, et al. Epstein-Barr virus and multiple sclerosis: interaction with HLA. Genes Immun 2011;13:14-20.

7. Brynedal B, Duvefelt K, Jonasdottir G, et al. HLA-A confers an HLA-DRB1 independent influence on the risk of multiple sclerosis. PloS One 2007;2:e664.

8. IMSGC. Genetic risk and a primary role for cell-mediated immune mechanisms in multiple sclerosis. Nature 2011; 476:214-219.

9. Thompson AJ, Montalban X, Barkhof F. Diagnostic criteria for primary progressive multiple sclerosis: a position paper. Ann Neurol 2000;47:831-835.

10. Dilthey A, Leslie S, Moutsianas L, et al. Multi-population classical HLA type imputation. PLoS Comput Biol 2013; 9:e1002877.

11. Cortes A, Brown MA. Promise and pitfalls of the immunochip. Arthritis Res Ther 2011;13:101.

12. Barcellos LF, Oksenberg JR, Begowich AB, et al. HLADR2 dose effect on susceptibility to multiple sclerosis and influence on disease course. Am J Hum Genet 2003;72: 710-716.

13. Dilthey AT, Moutsianas L, Leslie S, McVean G. HLA*IMP: an integrated framework for imputing classical HLA alleles from SNP genotypes. Bioinformatics 2011;27:968-972.

14. Rothman KJ. Epidemiology, an Introduction. New York: Oxford University Press; 2002.

15. Ahlbom A, Alfredsson L. Interaction: a word with two meanings creates confusion. Eur J Epidemiol 2005;20: 563-564. 
16. Statistics Sweden. Socioeconomic Classification SEI. Stockholm: Statistics Sweden; 1982.

17. Troy LM, Hunter DJ, Manson JE, Colditz GA, Stampfer MJ, Willett WC. The validity of recalled weight among younger women. Int J Obes Relat Metab Disord 1995; 19:570-572.

18. Internet-based information. Available at: http://www.scb.se. Accessed February 15, 2013.

19. Munger KL, Levin LI, Hollis BW, Howard NS, Ascherio A. Serum 25-hydroxyvitamin D levels and risk of multiple sclerosis. JAMA 2006;296:2832-2838.

20. Wortsman J, Matsuoka LY, Chen TC, Lu Z, Holick MF. Decreased bioavailability of vitamin D in obesity. Am J Clin Nutr 2000;72:690-693.

21. Bäärnhielm M, Hedström AK, Kockum I, et al. Sunlight is associated with decreased multiple sclerosis risk: no interaction with human leukocyte antigen-DRB1*15. Eur J Neurol 2012;19:955-962.

22. Subramanian V, Ferrante AW. Obesity, inflammation, and macrophages. Nestle Nutr Workshop Ser Pediatr Program 2009;63:151-159.

23. Weisberg SP, McCann D, Desai M, et al. Obesity is associated with accumulation of macrophages in adipose tissue. J Clin Invest 2003;112:1821-1830.

24. Lumeng CN, Bodzin JL, Saltiel AR. Obesity induces a phenotypic switch in adipose tissue macrophage polarization. Clin Invest 2007;117:175-184.

25. Mikita J, Dubourdieu-Cassagno N, Deloire MS, et al. Altered M1/M2 activation patterns of monocytes in severe relapsing experimental rat model of multiple sclerosis: amelioration of clinical status by M2 activated monocyte administration. Mult Scler 2011;17:2-15.
26. Maffei M, Halaas J, Ravussin E, et al. Leptin levels in human and rodent: measurement of plasma leptin and ob RNA in obese and weight-reduced subjects. Nat Med 1995;1:1155-1161.

27. Matarese G, Carrieri PB, La Cava A, et al. Leptin increase in multiple sclerosis associates with reduced number of CD4(+)CD25+ regulatory T cells. Proc Natl Acad Sci USA 2005;5:5150-5155.

28. Matarese G, Di Giacomo A, Sanna V, et al. Requirement for leptin in the induction and progression of autoimmune encephalomyelitis. J Immunol 2001;166:5909-5916.

29. Onkamo P, Väänänen $S$, Karvonen $M$, Tuomilehto J. Worldwide increase in incidence of type I diabetes: the analysis of the data on published incidence trends. Diabetologia 1999;42:1395-1403.

30. Warren SA, Svenson LW, Warren KG. Contribution of incidence to increasing prevalence of multiple sclerosis in Alberta, Canada. Mult Scler 2008;14:872-879.

31. Sjoberg A, Lissner L, Albertsson-Wikland K, Marild S. Recent anthropometric trends among Swedish school children: evidence for decreasing prevalence of overweight in girls. Acta Paediatr 2008;97:118-212.

32. Tremblay MS, Katzmarzyk PT, Willms JD. Temporal trends in overweight and obesity in Canada, 1981-1996. Int J Obes 2002;26:538-543.

33. Lumeng CN, Bodzin JL, Deyoung SM, et al. Increased inflammatory properties of adipose tissue macrophages recruited during diet induced obesity. Diabetes 2007; 56:16-23.

34. Olsson T, Hillert J. The genetics of multiple sclerosis and its experimental models. Curr Opin Neurol 2008; $21: 255-260$

\section{Minutes Pack a Punch}

\section{Neurology ${ }^{\circledR}$ Podcasts}

- Interviews with top experts on new clinical research in neurology

- Editorial comments on selected articles

- Convenient-listen during your commute, at your desk, or even at the gym

- On demand-it's there when you want it

- Fun and engaging

- New topic each week

- FREE

Listen now at www.aan.com/podcast 


\section{Neurology}

\section{Interaction between adolescent obesity and HLA risk genes in the etiology of multiple sclerosis}

Anna Karin Hedström, Izaura Lima Bomfim, Lisa Barcellos, et al. Neurology 2014;82;865-872 Published Online before print February 5, 2014

DOI 10.1212/WNL.0000000000000203

\section{This information is current as of February 5, 2014}

\section{Updated Information \& Services}

Supplementary Material

\section{References}

Citations

Permissions \& Licensing

Reprints including high resolution figures, can be found at: http://n.neurology.org/content/82/10/865.full

Supplementary material can be found at: http://n.neurology.org/content/suppl/2014/02/05/WNL.0000000000000 203.DC1

http://n.neurology.org/content/suppl/2014/02/05/WNL.0000000000000 203.DC2

This article cites 31 articles, 4 of which you can access for free at: http://n.neurology.org/content/82/10/865.full\#ref-list-1

This article has been cited by 8 HighWire-hosted articles: http://n.neurology.org/content/82/10/865.full\#\#otherarticles

Information about reproducing this article in parts (figures,tables) or in its entirety can be found online at:

http://www.neurology.org/about/about_the_journal\#permissions

Information about ordering reprints can be found online:

http://n.neurology.org/subscribers/advertise

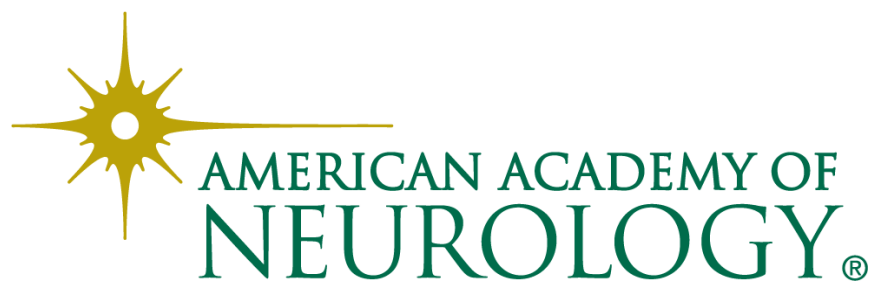

